\author{
Military Technical College \\ Kobry El-Kobbah, \\ Cairo, Egypt.
}

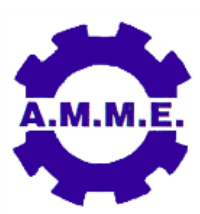

$17^{\text {th }}$ International Conference

on Applied Mechanics and

Mechanical Engineering.

\title{
SOLAR DISTILLER WITH FLAT PLATE COLLECTOR AND THERMAL STORAGE
}

\author{
M. A. Farahat ${ }^{1}$, M. M. Mousa ${ }^{2}$ and N. H. Mahmoud ${ }^{2}$
}

\begin{abstract}
Two conventional solar distillers and a thermal storage system with flat plate collector are designed and fabricated at Shebin El-kom city, Egypt at Latitude of $30.58^{\circ} \mathrm{N}$ and Longitude of $31.01^{\circ} \mathrm{E}$. The thermal storage system is used to collect the solar energy during daytime and store it in a thermally insulated water tank. Two types of experiments are conducted. Firstly, the productivity of conventional solar distiller through a daytime and night without heat recovery is measured. The second type prescribes measuring the productivity using both the direct solar energy during daytime and recovered the energy during night. The heat is recovered with the aid of a pumping system and through a heat exchanger immersed inside the salt water accumelated within the distiller basin. The results of two solar distillers with and without heat recovery are investigated. The daily productivity of solar distiller with heat recovery is almost twice of the conventional one. Present measurements show that the productivity of modified distiller is increased by 75, 94, 121 and 109 percentage for August, September, November and December respectively.
\end{abstract}

\section{KEYWORDS}

Solar energy; Solar Distillation; Thermal storage; Flat plate collector; Distiller modifications.

1 Demonstrator, Dept. of Mech. Power Eng., Menoufia University, Shebin El-Kom, EGYPT.

2 Professor, Dept. of Mech. Power Eng., Menoufia University, Shebin El-Kom, EGYPT. 


\section{INTRODUCTION}

Fresh water demand has increased dramatically in the last two decades. It has been recorded by Durkaieswaran and Murugavel [1] that fresh water demand per person increased from $75 \mathrm{~L}$ to $100 \mathrm{~L}$ per day in twentieth century. In addition, Kalogirou [2] reported that rivers and lakes' pollution has increased due to industrial wastes and large amount of sewage discharged. Oceans occupy $97 \%$ of salt water and the remaining fresh water is available in surface water, ice caps and ground water. Only 1 $\%$ is directly available for the need of the plants, animals and human life.

Solar desalination is not just the removal of sodium chloride salt from brackish or saltwater, but it can virtually remove any mineral and organic chemical compounds. It is a simple technology that is characterized by simplicity in design, fabrication and low operation and maintenance costs. Desalination methods such as vapor compression, reverse osmosis and electro-dialysis are used to provide fresh water. However, large amount of energy is needed for these methods. Misalignment between energy source and consumption is a main problem for using solar energy. Sun is not available at night. Hence, solar energy is considered as unsteady energy source. Thermal energy storage is an essential way to resolve the mismatch. There are three different mechanisms for energy storage: sensible heat storage, latent heat storage and chemical heat storage.

Solar distiller is a simple device which converts saline and brackish water into potable drinking water. Solar stills use evaporation and condensation processes similar to the cycle of water in nature rainfalls. Solar stills are classified into active and passive stills. Passive stills received solar energy directly which is the only source of energy. Active stills use additional energy to increase the evaporation rate. A lot of researches were carried out to increase the productivity or the efficiency of solar stills.

Extensive surveys [1-3] of literature pertaining to improving still performance have been presented. A solar still augmented with a flat-plate collector has been presented by Badran et al. [4]. It has been reported that the productivity has increased by $231 \%$ in the case of tap water as a feed, and $52 \%$ in the case of salt water as the feed. Pandy [5] has studied the effect of dried forced air bubbling and cooling of glass cover on the performance of solar distiller. Results showed that bubbling of ambient air, bubbling of ambient air after drying, bubbling of dry ambient air with cooling of glass cover and cooling of glass cover only increased distillate output by $7.1 \%, 33.5 \%, 47.5 \%$ and 30.5 , respectively. Experimental and theoretical investigations of solar desalination system coupled with solar parabolic trough has been carried out by Abdel-Rahim and Lasheen [6]. The results showed that fresh water productivity was increased on an average by $18 \%$. A new design of solar distiller with a hemispherical cover with and without cooling the surface was studied by Arunkumar et al. [7]. They showed that the efficiency increased from $34 \%$ to $42 \%$ for a fixed flow rate of $10 \mathrm{ml} / \mathrm{min}$ of water fed. This increase was obtained with a top cover cooling. A comparison between conventional and stepped solar still with external and internal reflectors has been carried out by Omara [8]. He showed that there is an increase in productivity by about $125 \%$. 
Stepped solar distiller with aluminum and cement absorber without and with auxiliary condenser and flat plate thermo-syphon were designed and tested by Mousa and Abd El-baky [9]. The results indicated that the daily productivity of cement absorber was $2.08 \mathrm{~L} /\left(\mathrm{m}^{2}\right.$.day) and increased by $18 \%$ using separated auxiliary condenser. They reported that the overall efficiency increased from $35 \%$ to more than $48 \%$. For the distiller with aluminum absorber, the daily productivity was $2.96 \mathrm{~L} /\left(\mathrm{m}^{2}\right.$.day) and increased to $3.49 \mathrm{~L} /\left(\mathrm{m}^{2}\right.$.day) using flat plate thermo-syphon and the overall efficiency increased from $50 \%$ to more than $65 \%$. Decreasing the shadow effect and maximizing utilization of solar radiation has been discussed using a conical cover by Gad et al. [10]. The daily productivity of both conical and conventional solar still were measured to be 3.38 and $1.93 \mathrm{~L} / \mathrm{m} 2$, respectively. Taamneh and Taamneh [11] have investigated the effect of forced convection on the performance of pyramid-shaped solar still. The daily productivity of freshwater was increased by up to $25 \%$ compared to free convection solar still.

Thermal storage systems are depending on converting solar energy into sensible heat in selected materials and recovering it when required. Xu et al. [12].Energy storage materials have been used to improve the performance of stills as reported by Sivakumar [13]. Using black rubber and black gravels as a storage medium in solar still has been examined by Nafey et al. [14]. They have been reported that using black rubber of thickness of $10 \mathrm{~mm}$ with the condition of brine volume of $60 \mathrm{~L} / \mathrm{m}^{2}$ improves the distiller productivity by $20 \%$. Also using black gravel with size $20-30 \mathrm{~mm}$ at the conditions of brine volume of $20 \mathrm{~L} / \mathrm{m}^{2}$ improves yield water by $19 \%$. A single slope single basin solar still with baffle suspended absorber was designed and fabricated by El-Sebaii et al. [15]. The baffled absorber decreases the preheating time of the basin water of solar stills. It is found that the daily productivity of the modified still is about $20 \%$ higher than that of the conventional still.

Sand is used as a sensible storage medium under the basin liner of solar still by ElSebaii et al. [16]. Experiments showed that a daily productivity of $4.005\left(\mathrm{~kg} / \mathrm{m}^{2}\right.$.day) with a daily efficiency of $37.8 \%$ has been obtained using $10 \mathrm{~kg}$ of sand compared to $2.852\left(\mathrm{~kg} / \mathrm{m}^{2}\right.$.day) with a daily efficiency of $27 \%$ when the still is used without storage. The annual average daily productivity of the still with storage is found to be $23.8 \%$ higher than that when it is used without storage. Abdallah et al. [17] examined the effect of using different types of absorbing material on the yield of solar stills. These absorbing materials are of two types: coated and uncoated porous media (called metallic wiry sponges) and black volcanic rocks. It is found that water collections was increased by $28 \%, 43 \%$ and $60 \%$ for coated, uncoated metallic wiry sponges and black rocks respectively. Storage tank system has been integrated with solar still by Voropoulos et al. [18]. Storage tank has been kept at a constant temperature using an electrical heater. It has been used as heat source for still through heat exchanger inside still. It has been reported that this design leads to higher distilled water output, due to higher basin temperatures as a result of hot storage tank water. Finally, It has been reported that It can exploit not only solar energy incident on saline water but also any other heat source available nearby, such as waste heat, conventional sources, electricity, solar collectors, solar pools, etc.

The previous review reveals that the basin and cover temperatures are the main parameters affecting the performance of the still. The productivity increases with the difference in temperature between basin and water. Thermal energy storage is 
necessary to save the available solar energy at a period of no load or when surplus energy is available and to make up for the shortage of energy when the load requires more energy.

The objective of the present study is to investigate the effect of using thermal storage system on the daily productivity of conventional solar distiller basin type. Conventional solar distiller and modified distiller with thermal storage system are presented experimentally. The thermal storage system consists of flat plate solar collector, recirculating pump and insulated storage tank. The thermal storage system is used for collecting solar energy during the daytime and store it as sensible heat of the fluid stored in the tank. The collected solar energy is then recovered during night with the aid of a heat exchanger immersed in the water of the distiller. The conventional solar distiller and flat plate collector oriented towards south in Shebin El-kom city, Egypt at Latitude of $30.56^{\circ} \mathrm{N}$ and Longitude of $31.01^{\circ} \mathrm{E}$. The daily productivity of conventional solar distiller and the effect of heat recovery on the daily productivity of modified solar distiller are aimed.

\section{EXPERIMENTAL SETUP}

An extensive experimental investigation has been performed under actual weather conditions. An experimental test rig has been designed, fabricated and assembled. A schematic diagram of the test rig is shown in Fig.1. It consists mainly of a conventional basin type and a modified basin still integrated with a thermal storage system through a coil immersed in the water of the solar distiller. The setup has been equipped with suitable instruments for various measurements and for controlling the system operation.

The conventional still is made from galvanized iron sheets $(1.5 \mathrm{~mm}$ thick) with a basin area of $1 \mathrm{~m}^{2}$. The wall height on the low-side is $150 \mathrm{~mm}$ and the high-side wall is 700 $\mathrm{mm}$. The whole basin surfaces are painted black internally to increase their absorptivity. Furthermore, the still is well insulated thermally with foam pads $(5 \mathrm{~mm}$ thick, $\mathrm{k}=0.02 \mathrm{~W} / \mathrm{m} \mathrm{K}$ ) to reduce the heat loss from the still to the ambient. Transparent glass window (5 mm thick), with 25 degrees angle of inclination, is used to cover the still. Silicon sealant was used to fill the gaps between glass cover and still body in order to prevent any vapor leakage to atmosphere.

Figure 1 illustrates the components of thermal storage system including a flat plate collector, a storage tank and the supplementary devices. The flat plate collector consists of 10 copper riser tubes and two headers are integrated together and well welded with a copper sheet. These components are contained in a box whose sides and bottom are insulated by foam pads while its top is covered by glass sheet. The dimensions of the flat plate collector are summarized in Table 1. A Tank of 80 Liters capacity was used with solar collector. The storage tank was insulated by glass wool insulation to decrease thermal energy losses. All connections, piping and hosing are insulated. In addition, a flow meter and valves are used to measure and control the water flow rate. A $0.5 \mathrm{HP}$ pump is used to circulate the water inside the collector and the tank to ensure a known and a constant flow rate of $2 \mathrm{~L} / \mathrm{min}$. The modified still has the same specifications and dimensions of the conventional still but it is coupled with 
thermal storage tank through copper coil as shown in Fig. 1. Copper coil made from copper tubes with diameter of 0.5 in and length of $8 \mathrm{~m}$.

Experiments have been conducted throughout the whole 24 hours for an extended period of time. Basin Saline water depth is controlled at $3 \mathrm{~cm}$. Thermocouples type T are used to measure temperatures at the locations illustrated in Fig. 1 and measurements have been recorded every 30 minutes. The productivity is measured every hour through all the day. Other measuring instruments as EPPLEY Pyranometer PSP used for measuring solar intensity in $\mathrm{W} / \mathrm{m}^{2}$, EXTECH Hydro Thermo Anemometer used for measuring wind speed in $\mathrm{m} / \mathrm{s}$ and scale glass flowmeter used for measuring distillated water in $\mathrm{mL} / \mathrm{hr}$ are also used. The thermocouples and other sensors are connected to MOLYTEK - M947002 Table Top Data logger for recording the data.

For solar water heating system temperatures of storage tank, glass cover, absorber metal plate, inlet and outlet of the collector have been measured. Also, the temperature of basin saline water, glass cover and absorber metal plate of each distiller have been measured. Uncertainties of thermocouples, Pyranmeters, flowmeter, anemometer and scale glass flowmeter are as follows: $\pm 1^{\circ} \mathrm{C}, \pm 10 \mathrm{~W} / \mathrm{m}^{2}, \pm 0.12 \mathrm{~L} / \mathrm{min}, 0.01 \mathrm{~m} / \mathrm{s}$ and \pm $0.5 \mathrm{~mm}$ respectively.

\section{RESULTS AND DISCUSSION}

The experimental program have been performed during the months from_August to December 2015. The measurements have been recorded throughout the daytime and night for both conventional distiller and modified distiller with heat recovery. The following figures present samples of measurements of the system's performance. The performance is monitored in terms of variation of component temperatures in addition to the hourly average productivity and the daily accumulated productivity.

Figure 2 presents the variation of global and diffused solar intensities through daytime and night with the local time of day. It is observed that, the solar intensity increases rapidly in the morning and attains a maximum value of at the noon, then it decreases approaching zero value at sunset. For flat plate collector, variation of the temperatures at inlet, outlet, cover, absorber and ambient are presented in Fig. 3. These temperatures are recorded during the operating period of thermal storage system. This period starting at 8:00 A.M. and ending at 4:00 P.M. It is seen that, the temperature difference between inlet and outlet is approximately constant with time till around 1:00 P.M. This means that the amount of heat added to the recirculated water is constant, in spite of the increase in solar radiation. Part of the solar radiation is stored in the absorber plate and other construction elements. Also, as the absorber temperature increases, the heat losses become larger, causing a smaller gain in useful energy. The temperature of the storage tank is an indication of the stored energy. Figure 4 illustrates that the storage tank temperature increases with the increase of solar intensity, reaching its maximum value at 4:00 P.M. At this time, the hot water drawn from the storage tank is used as a heat supply to the modified solar still to start the recovery process of stored energy. As a result, the tank temperature begins to decrease. 
Comparisons of absorber metal plate and basin saline water temperatures between conventional and modified distillers are shown in Fig. 5. The temperatures of conventional still follow the variation in solar intensity. However, the modified temperatures have the same behavior of the conventional sill but exhibit a sudden increase when the recovery system is started. This increase in temperatures is followed by an almost constant difference in temperatures for the rest of the day. Similar trends are observed for inner and outer glass temperatures of both distillers as shown in Fig. 6.

Figure 7 shows comparisons between the productivity of the conventional and the modified stills. From this figure it is observed that the productivity of both systems varies following the solar intensity. It can be seen also that the modified still productivity is much higher than that of the conventional one during the operation of recovery system. It is attributed to the higher evaporation rate from the modified still basin water according to the higher basin water temperature compared with that in the conventional still. A Variation in the productivity between two distillers in the period before the recovery is observed. This Variation could be due to the energy stored in the copper coil in the modified distiller. Figure 8 shows the change in the accumulated productivity around 24 hours. It shows that there is an increase of modified distiller productivity by $100 \%$ from that of the conventional distiller.

Figure 9 shows the accumulated productivities of both conventional and modified stills during the period of experiments. A pronounced increase in the accumulated productivity of the modified still is clearly noticed from the figure. The accumulated productivity is increased by 75, 94, 121 and 109 percentage for August, September, November and December respectively. It can be also seen that there is an overall decrease in productivity of both distillers because of the seasonal reduction in solar intensity during the winter. However, it is observed that the productivity of modified distiller is usually greater than that of the conventional distiller due to the recovered energy at night. The magnitude of increase in productivity amounts to a factor of 2 of the conventional still's productivity throughout the measured period.

\section{CONCLUSIONS}

This paper concerns with investigating experimentally the effect of thermal storage on the performance of solar distiller. The present work is based on designing and fabricating two distillers. One is conventional of the basin type and the other is modified and equipped with a thermal storage system. The thermal storage system is used to collect the solar energy with the aid of flat plate collector. The program of experimental work reported here was carried out at Shebin El-kom city, Egypt at Latitude of 30.58 $\mathrm{N}$ and Longitude of $31.01^{\circ} \mathrm{E}$. The experiments were conducted during a period included the months of August, September, November amd December of 2015 respectively. The obtained results showed that the productivities of the conventional solar distiller during the months of August, September, November and December 2015 are as 3.95, 3.33, 1.59 and $1.37 \mathrm{~L} /$ respectivily. While the productivities of the modified distiller which were recorded during these months are as follows $6.90,6.45,3.21$ and $2.77 \mathrm{~L} / \mathrm{m}^{2}$.day. 


\section{REFERENCES}

[1] P. Durkaieswaran and K. Kalidasa Murugavel, "Various special designs of single basin passive solar still - A review", Renewable and Sustainable Energy Reviews, Vol. 49, pp. 1048-1060, (2015).

[2] Soteris Kalogirou, "Survey of solar desalination system and system Selection", Energy, Vol. 22, No. 1, pp. 69-81, (1997

[3] K. Sampathkumar, T.V. Arjunan, P. Pitchandi and P. Senthilkumar, "Active solar distillation - A detailed review", Renewable and Sustainable Energy Reviews, Vol.14, pp. 1503-1526, (2010).

[4] Ali A. Badran, Ahmad A. A1-Hallaq, Imad A. Eyal Salman and Mohammad Z. Odat, "A solar still augmented with a flat-plate collector ", Desalination, vol. 172, pp. 227-234, (2005).

[5] G. C. Pandey, "Effect of dried and forced air bubbling on the partial pressure of water vapour and the performance of solar stil", Solar Energy ,vol.33, No. 1, pp. 13-18, (1984).

[6] Zeinab S. Abdel-Rehim and Ashraf Lasheen, "Experimental and theoretical study of a solar desalination system located in Cairo, Egypt", Desalination, Vol.217, pp. 52-64, (2007).

[7] T. Arunkumar, R. Jayaprakash, D. Denkenberger, Amimul Ahsan, M.S. Okundamiya, Sanjay kumar, Hiroshi Tanaka and H.Ş. Aybar, "An experimental study on a hemispherical solar still", Desalination, Vol. 286 , pp. 342-348, (2012).

[8] Z.M. Omara, A.E. Kabeel and M.M. Younes, "Enhancing the stepped solar still performance using internal reflectors", Desalination, Vol.314, pp. 67-72, (2013).

[9] Mousa m. Mohamed and Mostafa Abd El-Baky, "Thermosyphon solar water distiller of cement and aluminum absorber with auxiliary condenser", Int. J. Water Res. Environ. Eng., Vol. 3, No.13, pp. 308-323, (2011).

[10] H.E. Gad, Sh. Shams El-Din, A.A. Hussien and Kh. Ramzy, "Thermal analysis of a conical solar still performance: An experimental study", Solar Energy, Vol. 122, pp. 900-909, (2015).

[11] Yazan Taamneh and Madhar M. Taamneh, "Performance of pyramid-shaped solar still: Experimental study", Desalination, Vol. 291, pp. 65-68, (2012).

[12] J. Xu, R.Z. Wang, Y. Li, "A review of available technologies for seasonal thermal energy storage", Solar Energy, Vol. 103, pp. 610-638, (2014).

[13] V. Sivakumar and E. Ganapathy Sundaram, "Improvement techniques of solar still efficiency: A review", Renewable and Sustainable Energy Reviews, Vol. 28, pp.246-264, (2013).

[14] A. S. Nafey, M. Abdelkader, A. Abdelmotalip and A. A. Mabrok, "Solar Still Productivity Enhancement", Energy Conversion and Management, Vol.42, pp. 1401-1408, (2001).

[15] A. A. El-Sebaii, S. Aboul-Enein and E. El-Bialy, "Single basin solar still with baffle suspended absorber", Energy Conversion \& Management, Vol.41, pp. 661-675, (2000).

[16] A.A. El-Sebaii , S.J. Yaghmour, F.S. Al-Hazmi, Adel S. Faidah, F.M. AlMarzouki and A.A. Al-Ghamdi, "Active single basin solar still with a sensible storage medium", Desalination, Vol. 249,pp. 699-706, (2009). 
[17] Salah Abdallah, Mazen M. Abu-Khader and Omar Badran, "Effect of various absorbing materials on the thermal performance of solar stills", Desalination, Vol. 242, pp. 128-137, (2009).

[18] K. Voropoulos, E. Mathioulakis and V. Belessiotis, "Experimental investigation of the behavior of a coupled with hot water storage tank", Desalination, Vol. 156, pp. 315-322, (2003).

Table 1. Dimensions of flat plate collector.

\begin{tabular}{|c|c|c|c|c|c|c|c|c|}
\hline Specification & 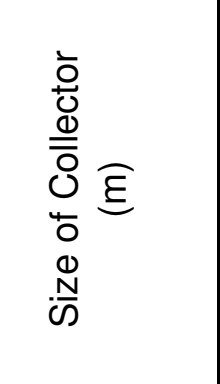 & 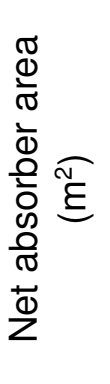 & 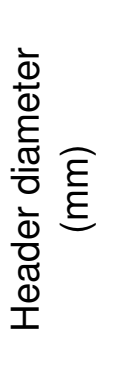 & 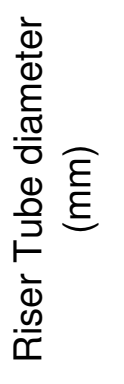 & 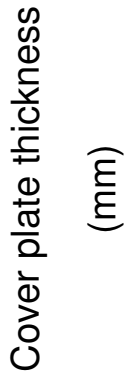 & 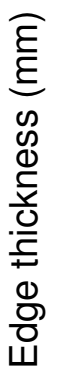 & 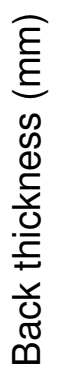 & 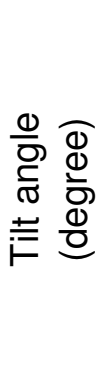 \\
\hline Dimensions & $\begin{array}{c}\text { Width=1 } \\
\text { length }=1.8 \\
\text { depth=0.07 }\end{array}$ & 1.6 & 19.05 & 12.7 & 5 & 50 & 50 & 20 \\
\hline
\end{tabular}
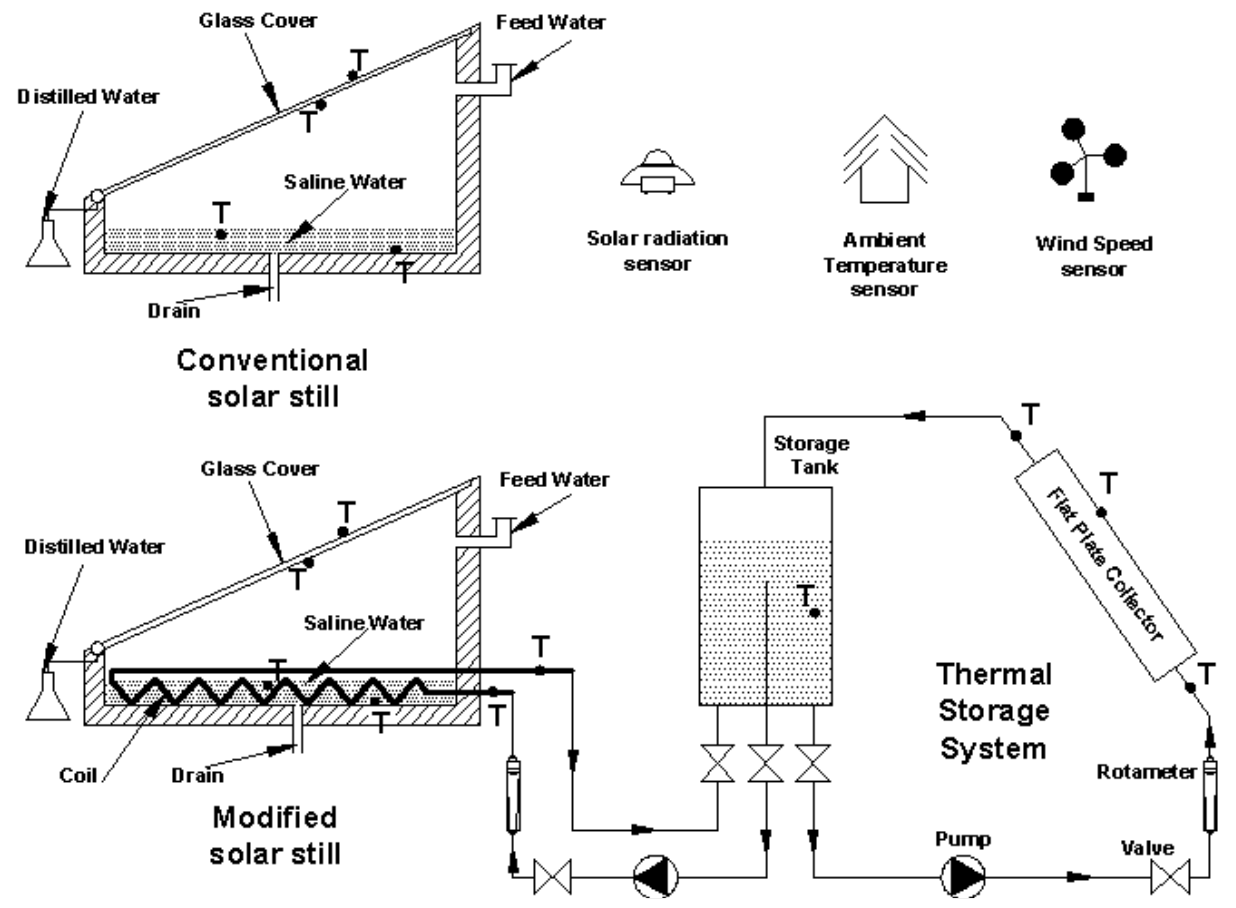

Fig.1. Layout of the experimental setup. 

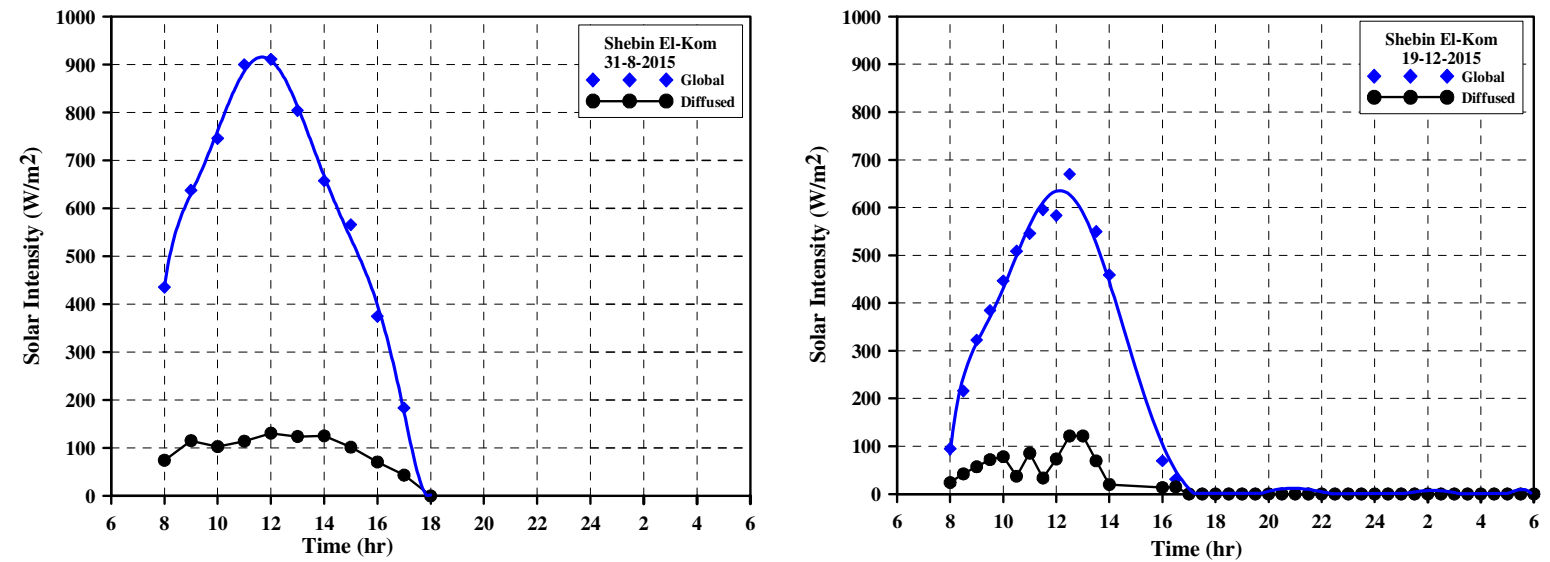

Fig.2. Variation of global and diffused solar intensity with a local daytime.
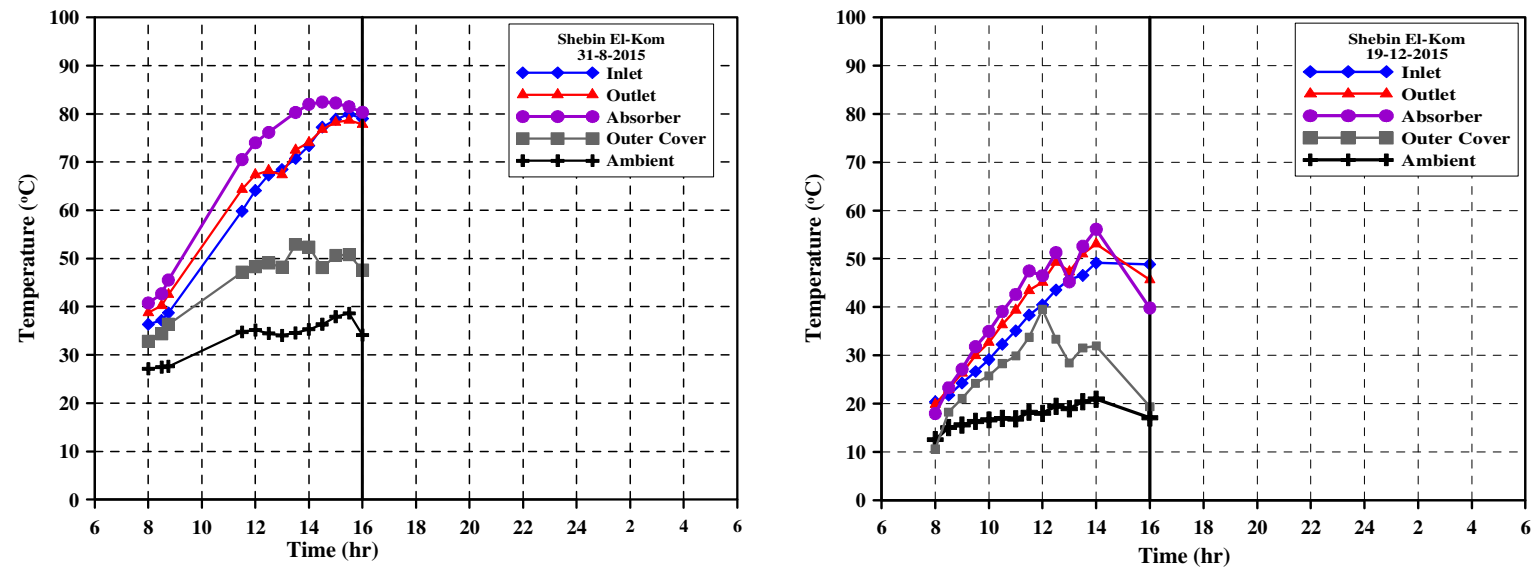

Fig.3. Variation of inlet, outlet, absorber, cover and ambient temperatures of flat plate collector with a local daytime.
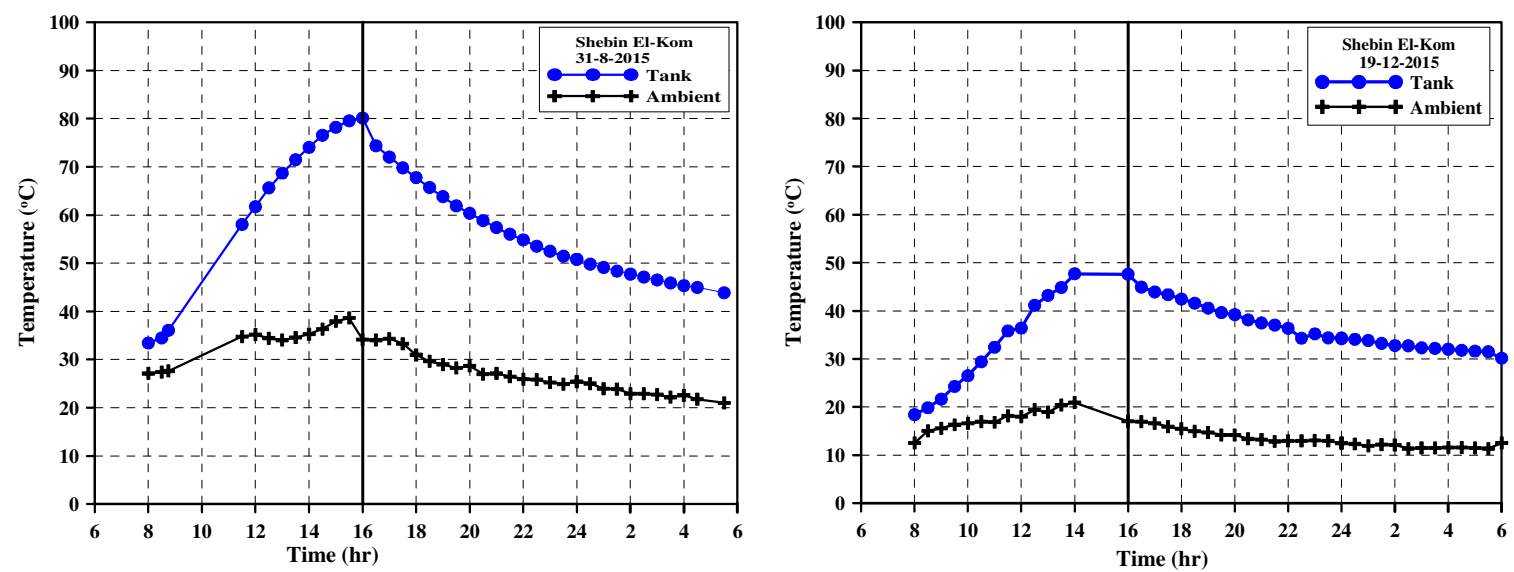

Fig.4. Variation of thermal storage tank temperature with a local daytime. 

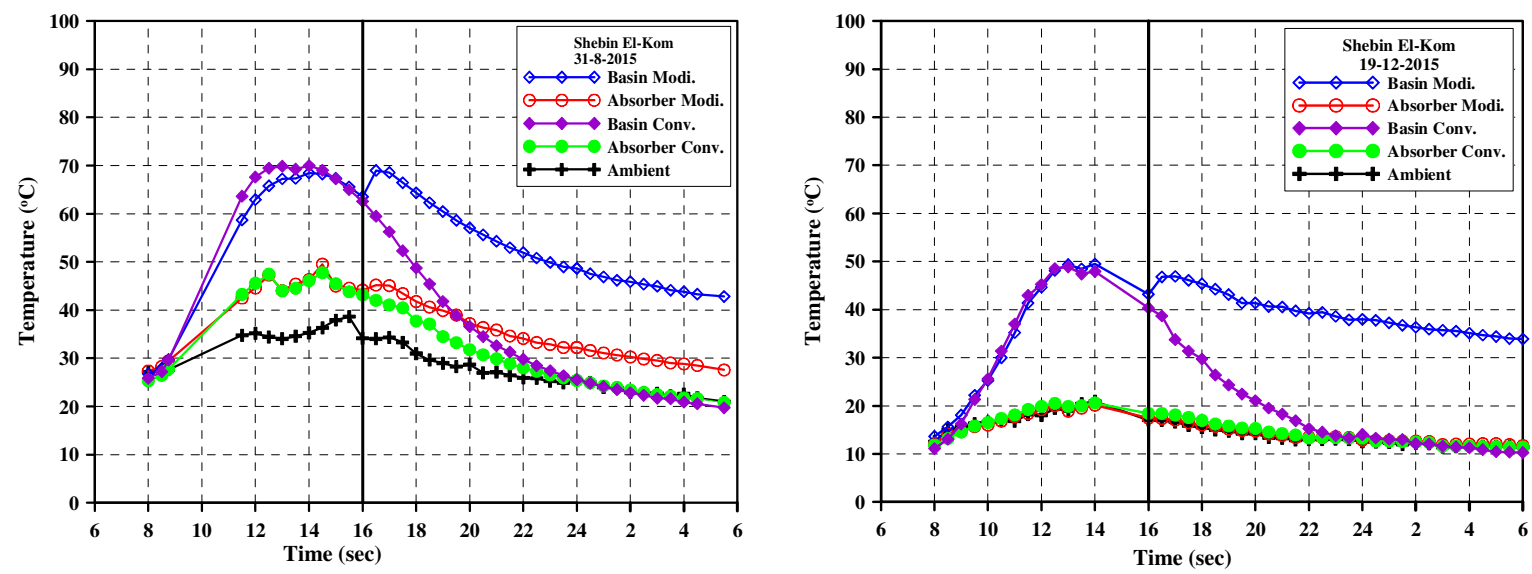

Fig.5. Comparisons between basin and absorber temperatures of conventional and modified distillers with a local daytime.
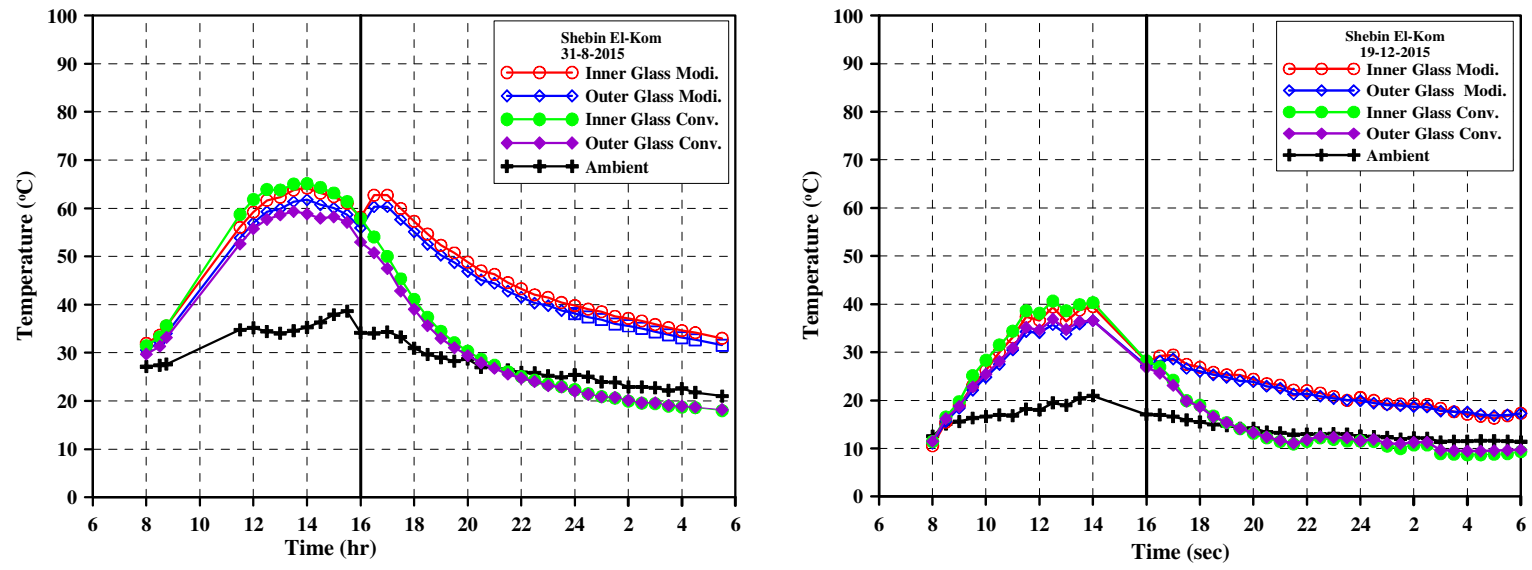

Fig.6. Comparisons between inner and outer glass temperatures of conventional and modified distillers with a local daytime.
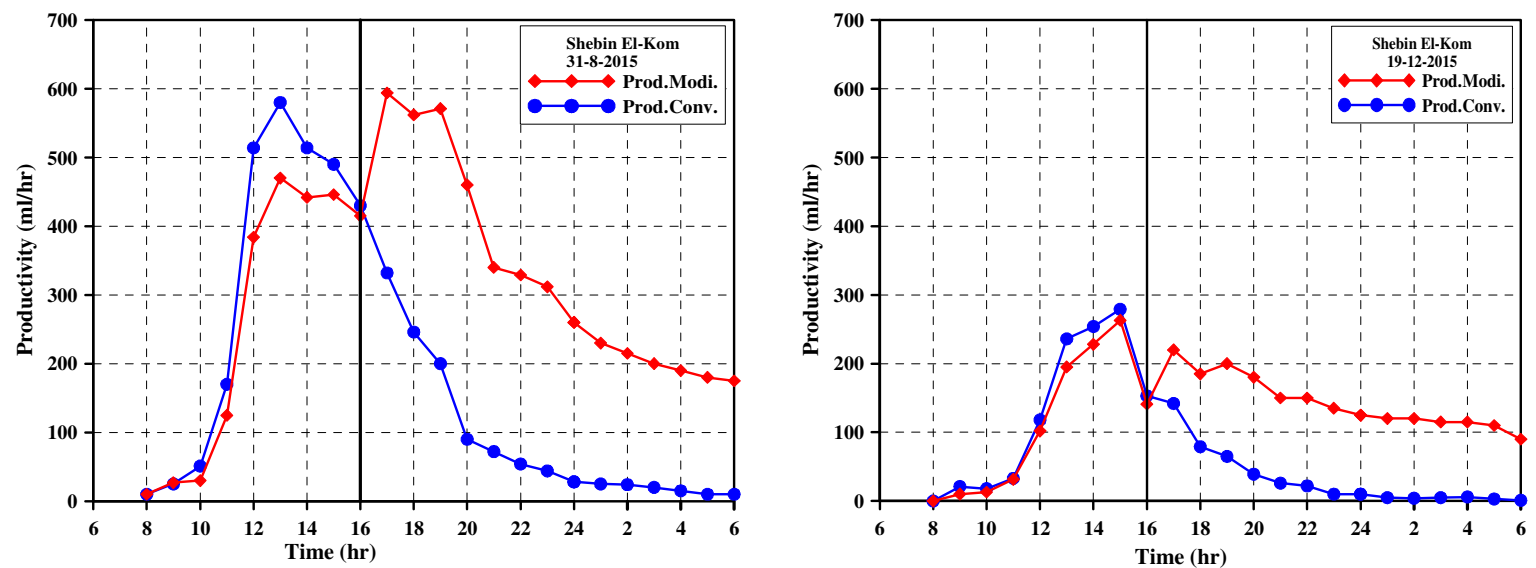

Fig.7. Comparisons between the productivity of conventional and modified distillers with a local daytime. 

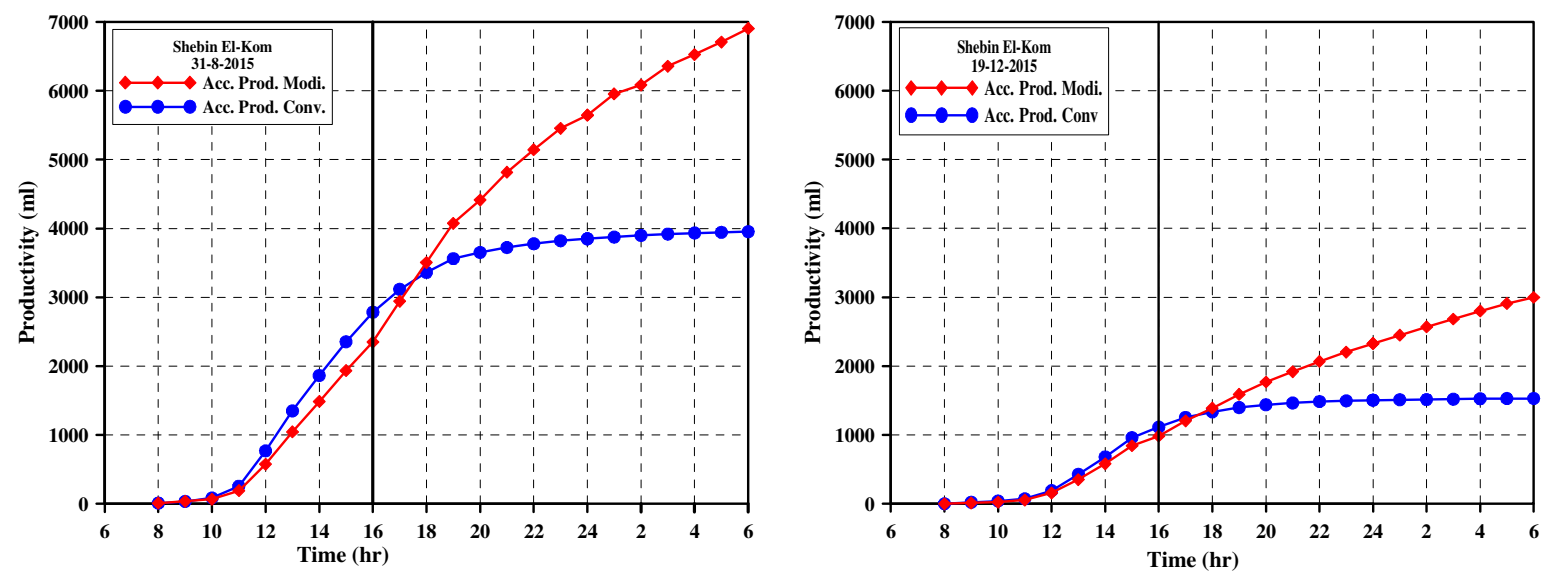

Fig.8. Comparisons between the accumulated productivity of conventional and modified distillers with a local daytime.

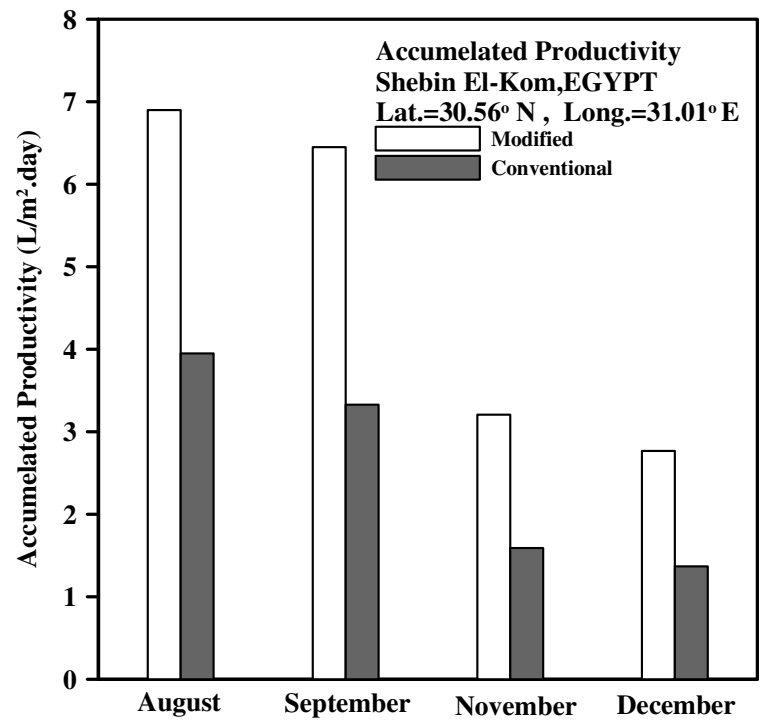

Fig.9. Average accumulated productivity of conventional and modified distillers during the period of experiments, 2015. 